\title{
WRITING SHORT FICTION FROM EXILE. AN INTER- VIEW WITH HA JIN
}

\author{
Jose Ramón Ibáñez Ibáñez, Universidad de Almería ${ }^{1}$ \\ Email: jibanez@ual.es
}

During the last two decades, Jìn Xuĕfềi, who goes under the pen-name of Ha Jin, has emerged as one of the most prominent Asian-American writers in America, with works in fiction, poetry and essays dealing with the Chinese experience in China and the U.S. Born in 1956 in the Chinese province of Liaoning, Ha Jin's life has been strongly marked by political and sociological events occurring in contemporary China. His father was an officer in the Red Army who was transferred around various provinces for years. This continuous change of residence gave young Jin the opportunity to discover remote regions, meet people and get acquainted with Chinese traditions and customs.

Ha Jin was ten years old when Mao Zedong launched the Cultural Revolution, which aimed at removing capitalism and Chinese traditions by way of the strict implementation of communism. Colleges were closed for ten years and many young people became Red Guards, an armed revolutionary youth organization aiming to eradicate the 'four Olds' Old Customs, Old Culture, Old Habits and Old Ideas - which were described as antiproletarian. At the age of thirteen, Ha Jin joined the People's Liberation Army as a way of leaving home as he declared in different interviews (Gardner 2000; Weinberger, 2007; Fay 2009). While in the army, he worked as a telegrapher, a post which allowed him some free time to read literature and educate himself.

He left the army in 1975 and worked for three years in a railway company. In 1977 colleges reopened in China and, a year later, Ha Jin began his studies at Heilongjiang University where he earned a B.A. in English in 1981. He then decided to pursue his studies in Anglo-American literature at Shandong University, where he received his M.A. in 1984. A year later, he won a scholarship to study American literature at Brandeis University, from which he earned a Ph.D. in English in 1993. While he was at Brandeis, Jin saw on television the Tiananmen Square massacre, an incident which split his life in two: along with his wife, he decided to remain in the U.S. as a refugee. This political incident made him realize he could never go back to China and teach in a state-controlled educational system. After a series of odd jobs, Ha Jin was offered a teaching position at Emory University. Later on, he moved to Boston University where he currently teaches literature and creative writing.

\footnotetext{
${ }^{1}$ Date of reception: 17 July 2014

Date of acceptance: 29 September 2014
} 
His literary career began with the publication of poetry: Between Silences (1990) and Facing Shadows (1996). He soon turned to short fiction, a genre which Ha Jin claimed he feels more at home with than with any other (Fay 2009). To date, he has published four collections of short stories: Ocean of Words (1996), Under the Red Flag (1997)-for which he received the Flannery O'Connor Award for Short Fiction -, The Bridegroom (2000) and A Good Fall (2009). He has also published six novels, among which are the criticallyaclaimed Waiting (1999), awarded with the National Book Award for Fiction in 1999 and War Trash (2004), a finalist for the Pulitzer Prize. His latest novel to date, Nanjing Requiem (2011), is a fictional account based on a historical episode, the Rape of Nanking, a mass murder that ocurred following the capture of this city by Japanese troops in 1937. A Map of Betrayal, a novel set in the U.S., is scheduled for its release on 4th November 2014. Interest in his works is evinced by the number of studies dealing with the immigrant experience (Juncker 2010; Kong 2012), the transnational identity (Marting 2011), or the bilingual creativity (Zhang 2002; Gong 2014) of his fiction.

Initially, Ha Jin did not consider the idea of becoming a writer as his main goal was to work as a translator. He knows that writing in English, though viewed as a betrayal of his mother tongue by many Chinese (Fay 2009), was his only option if he wanted to have his books published after the banning of the majority of his oeuvre in China. His fiction has been described as harsh, marked by a subtle fierce irony, his male characters finding themselves in precarious situations, harassed by either Chinese authorities or the grim conditions they experience when living in the United States.

As many others, this interview took place at Ha Jin's office at Boston University. What follows is an edited transcript of our talk recorded by the interviewer, with the kind permission of the author. However, due to time constraints, several questions were answered via e-mail exchange.

inteRvieWeR: In many interviews published in online magazines and literary reviews, you have chronicled the most salient features of an amazing life. You were a teenager when Chairman Mao launched the Cultural Revolution in 1966. What do you recall of those years?

Ha Jin: Well, soon after the Cultural Revolution was launched, the schools in China were closed and I couldn't get an education. I remember that it was difficult period for my family and we suffered a lot. For example, my mother was criticized severely as my grandfather had been a landowner. She was insulted and even thrown into a trash can . Soldiers also came to my house and took out all the books my father owned and burned them in a bonfire in the city's streets.

inteRvieWeR: Yes, but you decided to enrol as a Little Red Guard?

Ha Jin: Yes, that's true. There was not much to do at that time. I could not go to school and I decided to become a Little Red Guard. We spent most of the time singing 
revolutionary songs . Later on, before I even turned fourteen years old, I signed up with the People's Liberation Army .

inteRvieWeR: What do you remember about your time in the army?

Ha Jin: I remember I was sent to the Russian border in my first year. It was at the end of 1969 and there were rumors that the Soviet Union would attack China. We were off the coast of Russia and we did not have enough food: there were no vegetables or they were frozen. When we had some, we tried to eat as fast as we could . Many soldiers developed stomach problems at that time. I was a regular artillery man for a year and a half and my duty was to carry the shells . Half a year later, in 1970, I was picked to be trained as a telegraphist. It took me a long time to finish the training, but it also gave me some free time. inteRvieWeR: Was it then when you began studying English?

Ha Jin: It was a little bit after, when I left the army . I was determined to go to college but universities were still closed. I got a position as a telegrapher at a railroad company and, since I had some free time, I began to listen to a radio station that broadcast an English-language program six days a week . That's how I began, listening to half-hour radio programs . However, studying English was not in my plans as I preferred to study literature or world history .

inteRvieWeR: When schools reopened in 1977, you went to study English at Helongjiang University in Harbin. A few years later, you joined the Master's Program in American Literature at Shandong University. Did you decide to continue your education in the U.S. after your graduation?

Ha Jin: Well, entering a Master's Program in a Chinese university was really tough at that time. Some of those programs had foreign experts who came to teach courses . Many of them were American professors whom we befriended. It was one of them, Beatrice Spade who encouraged me to do graduate work in American literature in an American university . It was a natural step and, as most of my classmates in that program, I came here to continue my education. I joined the $\mathrm{Ph}$.D . program in American literature at Brandeis University, here in Massachusetts .

inteRvieWeR: And when you were here pursuing your doctorate and with the idea of returning to China after your graduation, your plans were shattered by the incident at Tiananmen Square in June 1984. It seems to me that your whole existence and that of your family was split in two. After watching on television the response of the Chinese government against student protests, you and your wife decided to remain in the U.S..

Ha Jin: Yes, it is true. It was really shocking to watch those scenes. For days, my wife and I were glued to the television screen. We couldn't believe our eyes . As a soldier, I was instructed to serve and protect the people and here we were watching the goverment's 
response to peaceful student demonstrations . It was then clear to me that I could not return to China and serve a state like that . Besides, since most schools were run by the state, I was pretty sure I would never get a state appointment . inteRvieWeR: Have you returned to China ever since?

Ha Jin: Well, it was in 1985 when I left China to come to study here, and I have never been able to go back. I cannot return as authorities have always refused to issue a visa . However, I've been to Taiwan and Hong Kong a few times, years ago, when it still belonged to Great Britain, but I have never returned to the mainland . If I went back, I would have to write a kind of self-criticism to express my remorse and to promise that I would not write anything against the government. And there is also lot of paperwork and no guarantee that you'll get approved. So it is not worth the effort .

inteRvieWeR: Do you consider that things could change so drastically in China and you will be able to return and be accepted by your people?

Ha Jin: I don't think it is that easy! My mother was hospitalized in fall 2011 and, even though I applied for visas, I was always denied the possibility of getting one .

inteRvieWeR: Is it because you are considered as a stygmatized author in China?

Ha Jin: Maybe, I'm not sure. You see, in China, the Government have different departments, like the Department of Foreign Affairs, the National Security Department, or the Propaganda Department . Since I might be blacklisted, they refused to issue a visa for me.

inteRvieWeR: In the "Preface" to your first book of poems, Between Silences (1990) you contend that you viewed yourself as a fortunate Chinese who wanted to "speak for those unfortunate people who suffered, endured or perished at the bottom of life and who created the history and at the same time were fooled and ruined by it" (1990:1). Years later, in The Writer as Migrant (2008) you admitted "my decision to leave contemporary China in my writing is a way to negate the role of the spokesmanship I used to envision myself. I must learn to stand alone, as a writer" (2008: 28). Does this mean that you initially intended to become a spokesman of those who suffered in China and then you realized that, as a person detached from his home country, you cannot speak for contemporary China anymore?

Ha Jin: I would not say that I intended to be a spokesman. I was quite sincere in the beginning but, of course, that sincerity was based on some kind of ignorance . I wrote that preface in 1988, a year before the massacre at Tiananmen Square. At that time, my plans were to return to China but after the incident, I realized that it wouldn't be possible . In a sense, a writer's writing cannot be separated from his existence and, besides, my situation has completely changed since I wrote those words . I think that the view of responsibility, 
of spokesmanship is beyond my ability . In a way it was also not ethical if I didn't live together with the Chinese or the people I was supposed to speak for . In other words, all the complexities and the later happenings somehow worked against that kind of assumption or preassumption .

inteRvieWeR: In the same book, when you tell the story about Alexander Solzhenitsyn, his exile, his refusal to become a U.S. citizen, his return to Russia and the time it took him to be accepted by his people, you claimed that you intended "to illustrate the fragility of his identity as a spokesman for his people" (2008:11). Could it be also in some way a reflection of a longing for your homeland?

Ha Jin: I don't know, honestly, I don't really know . But in his case I talk about his citizenship ceremony he didn't attend, although he had planned to go . It could have been a mistake but it shows that a small thing can change a writer's identity easily. But I also emphasize that his return was not that successful; in fact, it was the work that eventually made him be accepted by the Russians. In my case, I am not sure, but my job is to write good work, that's the only thing I can do, try to do my best .

inteRvieWeR: In your case, do you see yourself as the Chinese writer Lin Yutang (18951976) who established himself as "a cultural spokesman of China," thus aiming "to present Chinese culture to a Western audience" (2008:17)?

Ha Jin: No, I don't think of it that way because I write in English. Unlike Lin Yutang I have not published much in Chinese and he had been established as a writer in Chinese, even before he arrived in the United States. In my case, I am in a different situation . I've just tried to write good books related to China and the Chinese people, but I don't mean to be an interpreter .

inteRvieWeR: In The Writer as Migrant, you recall how Stanisław Baranczak, a Harvard professor of Polish, believed that exiled writers may experience inability when they try to achieve a linguistic playfulness because the writer "chooses to write in another language partly because he speaks to an audience in his adopted country who have different cultural and linguistic references and cannot fully understand him" (2008:49). Do you think that could be your case?

Ha Jin: To some degree, but I think it is not something unsurmountable . It can be resolved as I think that a non native speaker can still make jokes . Nabokov already set up the example: by using fragmentation and distortion he could crack jokes and create a different kind of humor. So there are different ways of making jokes and there are some jokes that are not bound to language or culture; they are like wit, they somehow remain intact when they are translated . 
inteRvieWeR: Finally, you acknowledged that "only through literature is a genuine return possible for the exiled writer" (2008:21). Have you returned to China through your literature?

Ha Jin: I would say to a certain degree. For instance, the reason why my novel Nanjing Requiem (2011) has been well-received is because it has not been manipulated by Chinese authorities . I think it is possible and that is something we can hope for .

inteRvieWeR: In your analysis of the language of migrant writers you talked about "strength, elegance, jokes, witticisms, playfulness, etc." In your short story collections, there are humorous fictional remarks (for instance, "A Bad Joke" or "Winds and Clouds Over a Funeral"), neutral English expressions sprinkled with Chinese proverbs, idioms or puns that may be either shocking or surprising to Western readers. Would you consider it to be a hint of nostalgia or just an oriental touch?

Ha Jin: I would say neither . This is in part because I started writing poetry - also my graduate work was done in poetics - and this fact made me more aware of the language . I think it would be something I might be able to bring into the language, to make the language a little bit fresher. So it is not meant to give the language exotic touches as my intention is to make something new in the language .

inteRvieWeR: To what extend can your readers fully grasp the meaning of certain Chinese idioms, or understand your own background or your characters' background?

Ha Jin: You know, I'm not sure about that; but I think when I write I don't have a specific group of readers in mind, though I do have the English ear; in other words, I do ask myself whether the English ear can catch a certain phrase or idiom . However, most of the idioms are just not translatable or cannot be transcribed from the Chinese into English . In this regard, they are often adapted and I do really recreate them in order to make them more acceptable to the English ear. Finally I would say most people can catch the hidden meanings .

inteRvieWeR: In your short story, "The Bridegroom," the narrator states the following: "although the sparrow is small, it has a complete set of organs" (Jin 2000a: 95). Is this a calque for a Chinese idiom? Does the expression refer to the Four Pests Campaign, most particularly the Great Sparrow Campaign, as one of the actions undertaken by Chinese authorities in the Great Leap Forward?

Ha Jin: Yes, in a sense, you are right. Nevertheless, I truly believe that the idiom dates back to much earlier times than the Great Sparrow Campaign initiated by Mao Zedong. However, the Chinese idiom was slightly different, as it referred to the five organs inside the body of a bird. In other words, the saying or the idiom gave point to the fact that despite its tiny size, a sparrow has everything in there . Thus, the Chinese expression says 
that birds have five organs, but I had to change that in English and I used the expression "complete set of organs".

inteRvieWeR: Do you still struggle with the English language?

Ha Jin: Yes, certainly. In my fiction, many of my characters often speak other languages or else they fall back on different linguistic registers . As a result, as a writer, I have to decide on what kind of English to let my characters speak, sometimes because they use idiomatic vocabulary or a dialect quite different from standard English .

inteRvieWeR: You began your literary career writing poetry. Do you feel that this genre is more suitable to express such feelings as homesickness?

Ha Jin: Well, I think that fiction can fulfill that feeling too. However, poetry is more personal, more emotional and, in that sense, maybe it is a more suitable form than fiction. In fiction you need more drama, so it is a different kind of expression.

inteRvieWeR: In an interview you established that the short story was your favourite genre as you can get into a short story and get out of it easily whereas if you work on a novel, you have to immerse yourself completely in it for a long time (Thomas 1998). To date, you have published six novels and four volumes of short fiction. Do you still feel more comfortable with short distance fiction than with long distance writing?

Ha Jin: It really depends on what I work at. It is like playing a specific sport - it needs different muscles. Thus, if I decide to work on short fiction, then I have to quit other things, stop writing novels because I have to train myself for the task. At the moment, I am in the middle of a novel, so that is a different kind of game . But when I worked on my most recent collection, A Good Fall, it really took me a while to get back in shape for the job, because I did not have the feeling for a while . I really had to keep writing in order to get the feel of short fiction. I had to train my mind to adapt myself.

inteRvieWeR: Do you consider the short story to be a more challenging and difficult form to apprehend?

Ha Jin: Short fiction is hard in some ways, but the novel is also hard because it is bigger, it is a more "physical" form. You have to hold an entire story, hundreds of pages, in your mind all the time - and it takes a lot of time and energy . But the short story is different because everything has to be accurate, everything is measured by words and sentences . Every touch must be accurate, so in this sense it is a different kind of sport .

inteRvieWeR: Who do you feel spiritually closer to, Chekhov, Nabokov or Conrad? 
Ha Jin: I feel spiritually closer to Chekhov even though I admit that the other two writers established a tradition . I do feel myself inmersed in that literary tradition - writers who wrote their works in English although they have a different language background . But when I am immersed in short fiction, I always read Chekhov very intently.

\section{inteRvieWeR: Is it because Chekhov is popular in China?}

Ha Jin: Not really . The Chinese do not read Chekhov . Only the highly literate may read Chekhov, but most people may not be interested in his short stories. When I was in China, we could only have access to contemporary translations of classical Russian fiction. We read the great masters of Russian literature, Tolstoy, Dostoievsky, Gogol, Turgenev or Chekhov and I feel I was nourished by their books. Chekhov soon became a very important literary source for me and I regard him as a godlike figure of short fiction. You cannot circumvent him: he is a great figure and I feel comfortable to work under his shadow.

inteRvieWeR: In his seminal work on the short story, The Lonely Voice, the Irish writer Frank O'Connor contends that the "short story has never had a hero" but it has instead "a submerged group of population" (2004: 17). That group of population changes from generation to generation and from writer to writer. Thus, in Gogol's stories, the submerged group of population would be 'officials, ' 'serfs' in Turgenev, 'prostitutes' in Maupassant or 'provincials' in Sherwood Anderson. Do you agree with O'Connor's view or do you consider his understanding of the short story cannot be applied to current short fiction?

Ha Jin: Frank O'Connor's is a wonderful book. I assume that the short story does not have a hero, but it has a different kind of populace. I think it perhaps has something to do with the scope because the space will not allow that . When you have a hero, you really have a kind of comprehensive presentation of that person. It needs many pages to develop that person thoroughly. The short story does not work that way. So on the whole, I tend to agree: I really can't remember a hero, you have different kinds of people but you don't have someone like Leonald Bloom in Ulysses. In a novel you create a mind, but in a short story you don't have enough space - you have to be very suggestive, describe things in an indirect way .

inteRvieWeR: The Cultural Revolution closed down schools. It also aimed to destroy the old culture and pursue the capitalist influence from abroad. How is this revolution reflected in your short fiction?

Ha Jin: It affects the worldviews of both narrators and characters . This also varies from book to book. The Cultural Revolution figures more evidently in Ocean of Words and Under the Red Flag. 
inteRvieWeR: Your fiction has often been billed as stark, harsh, with little room for hope. To what extent do past experiences in China influence your literary perception?

Ha Jin: Well, it depends on which book we are referring to. For example, my last short story collection, A Good Fall has quite a bit of hope in it. Since I spent my first twentynine years in China, it is understandable that both my sensibility and worldview are somewhat shaped by those years and places I had lived in . In this sense, China is always part of my being, which I do not particularly like but have to accept . Because I live outside China, I can look at it from an objective perspective and distance.

inteRvieWeR: In your short stories, it is noticeable that there exists a special sympathy towards common folk and those living on farms and/or small communities as it can be seen in the protagonists in "Again the Spring Breeze Blew", "Sovereignty" (Under the Red Flag) or "A Bad Joke" (The Bridegroom) just to name a few stories. Isn't it a kind of "pastoral view" of society?

Ha Jin: Well, I grew up in the countryside because my father was an army officer, so we moved around a lot and I spent many years in small rural towns. You know, I don't think there is a pastoral view of society in Under the Red Flag and, in fact, many readers are disturbed or terrified by events. For a lot of people, the book is too stark, too harsh. However, I think there are sweet and happy moments, such as in "New Arrival" . In that short story collection [Under the Red Flag] as well as in my novel Waiting, I really tried to preserve a lot of things, because to my mind, a lot of customs and things might be vanishing. So, I was just trying to preserve them in words .

inteRvieWeR: And in these stories there is always a subtle critique. Do you think it could be the reason why your books have been banned in China?

Ha Jin: Yes, I think so. Many people think my books are a distorsion of reality, but I've portrayed the world the way I see it . I have never written to a kind of ideal reader . If my fiction were translated into Chinese, I believe that it would be accepted by the Chinese. Some critics have used the term 'Orientalism' to refer to my fiction. I do consider it irrelevant. My writing does not cater for all tastes, let alone Western readers .

inteRvieWeR: Leslie Epstein, who taught in the master's program you enrolled at Boston University, declared that "Ha Jin was one of the great poets of rape" (Gardner 2005). Jhumpa Lahiri, the highly acclaimed short story writer and novelist, who was also in the same master's program contended that your stories were harsh and "pushed people's buttons" as there were "lots of brutal rape scenes in them" (Gardner 2005). Rape is a common feature in your fiction. However, there are also many references to adultery in your narrations set in either China or the USA. Stories such as "In Broad Daylight" and "Resurrection" (Under the Red Flag) or "Broken" (The Bridegroom) hinge on "the capital sin," but a more painful suspicion also exists in "The Woman from New York" 
(The Bridegroom) and "The Beauty" (A Good Fall). Is adultery regarded as a deadly sin in both Chinese culture and tradition?

Ha Jin: It was in the tradition, but it varied from dinasty to dinasty . However, during the decades I grew up in, it was a huge problem, a crime . Lots of people were punished because of adultery and those stories you've mentioned are all based upon actual happenings. Some of those incidents I collect in my novels and short stories where either witnessed or heard about when I was a young boy . I just couldn't get them out of my mind and, in this sense, writing them was rather therapeutic. As a young child, you just cannot forget what you saw - I was an eye witness to the events described in "In Broad Daylight": I remember seeing the woman being paraded, being denounced on the street because of her adultery though I plotted a different story end . But, yes, it is true, I just simply couldn't forget those scenes . inteRvieWeR: In many of your stories, many characters-comrades and primarily officials-described adultery as a bourgeois sin, a manifestation of the corrupted Western world modes. Did you hear that when you were young?

Ha Jin: Yes, it was described that way, but it was not regarded as foreign though. The question in terms of humanity was not foreign though it was described as something bourgeois . However, this idea of being a dreadful 'sin' inherited from the West is something people said although, needless to say, it was not true. Adultery was persecuted and punished in many ways in Chinese culture . Later, I came to know that and that's why I got so bothered by the propaganda .

inteRvieWeR: So Chinese authorities could ruin a person's life, and that is what happened to Zhu Wenli, the protagonist in the story "A Decade" (Under the Red Flag), a schoolteacher who was accused by her students and eventually banished to a remote area of rural China.

Ha Jin: Yes, you're right. That story was also based upon an actual happening.

inteRvieWeR: Your short stories collections follow a pattern which appears to be based on accounts which occurred in your own life. Thus, Ocean of Words would be an autobiographical review of your past military life whereas Under the Red Flag unveils culture and tradition in the rural China of your childhood. The third volume, The Bridegroom, though still set in rural China, foreshadows a slight opening of China to the Western World. Finally, the stories of A Good Fall deal with the misfortunes of Chinese characters in America as they struggle to survive in a hostile society. In all of your stories, no matter where they take place, there seems to be little hope for your characters. Have you considered the possibility of writing about Chinese immigrants improving their living conditions in the US?

Ha Jin: Well, in A Good Fall, there are moments, there are stories in which hope is there. For instance, the story of Chinese prostitutes ["The House behind a Weeping 
Cherry"] which ends with the young man [Wanping] trying to find a life with his girlfriend [Huong], who gave up prostitution and fled with him so as to find a better life in America. Some Chinese readers found the end too optimistic though . But in reality there is room for new immigrants to find a decent life in the United States. Indeed, I have a few stories where you can find hope and possibility. In "A Good Fall" [A Good Fall] the monk [Ganpin] had a fortunate "fall" but, of course, it was after a great loss .

inteRvieWeR: Ocean of Words (1996) is your first collection of short stories. My impression is that the events in some of those narratives, though fictional, are deeply rooted in your own life experience as a soldier in the border between China and the Soviet Union. Since you worked as a telegrapher, is the story "A Love in the Air" based on a true account or it is mainly fictional?

Ha Jin: It is fictional but based upon several happenings that occurred when I was a soldier . I put them together, but it is true that people had affairs over the air, on the radio, because those people had a certain telegraphic style: they could actually find out whether the other person was a female telegrapher. If they were discovered having an affair over the air, they would eventually get discharged . But in this story, I invented a lot of details

inteRvieWeR: Most of the stories in your second volume of short fiction Under the Red Flag (1997) take place in rural China. Would you say that the Chinese society featured in those stories, in which the components of ancient tradition and customs as well as superstitions have a paramount importance, corresponds to the China where you lived as a teenager?

Ha Jin: Yes, I think so. I described the places and the people the way I saw them. I believe the stories are faithful to the customs, the people and also the moment in history .

inteRvieWeR: Not long ago, I heard on the news that in a hospital in China, homosexuality was being treated as an illness and that gay patients were undergoing electroshock therapy as a remedy for their malady. This situation reminded me of "The Bridegroom" (The Bridegroom), a story that can be read as a comic satire of the old times. However, that piece of news made me think that certain popular beliefs and superstitions still lingered on in modern China. Did you initially think of this story as a satire of what happened in traditional China or as a denunciation of common practices in current China?

Ha Jin: In current China I am afraid it is still the same . To give an example, a few days ago an article was published about a wife who married a gay man . It said that there was an estimated ten thousand women living in this situation. That article also made reference to the story of a woman in her sixties who was still a virgin and still married to a gay man . These women wouldn't get a divorce because they loved their husbands and they did not know that they were gay. These men were using their wives as some sort of camouflage 
and they could live their lives and not be bothered by people. This is still a problem, but very few Chinese writers would write about it .

I decided to write that short story, "The Bridegroom," to make the book a little bit richer. Homosexuality was a big topic and a big confusion for those people. Very few writers would like to touch on that, and that is why I decided to tackle this subject and expose those people's experiences . In a way, the story was purely created by willpower as I began to do research and I put all the details together . That article I mentioned stated that there were about ten thousand women in sexless marriage, and you can see how big the problem is . My intention was not to denounce it, but to show that something was happening to a group of people and how their lives were misshaped and, still, they managed to survive . In fact, in "The Bridegroom", the story is told by a narrator who is the gay man's father-in-law . He is depicted as a decent person who refuses to step out of his sex morality. There is a limitation although he shows empathy. Thus, the story becomes a narration about him as well . It is a story about real happenings and wives in these marriages did not want to break the union .

inteRvieWeR: Do you see any progression in your fiction as your first two short story collections displayed a subtle critique of the Chinese regime whereas in the last one, A Good Fall, China is left behind even though Chinese immigrants in America are still worried that the tentacles of the Chinese government may reach them?

Ha Jin: Yes, the authorities still loom large over those characters, whose lives can be affected if they are discovered to be in an irregular situation. It is true, there is a progression and the first of the connections was the Chinese military experience, but step by step, you see, the reason of this movement is because I settled in the United States .

inteRvieWeR: Although you seem to be living "the American dream", the characters in some stories of your last collection A Good Fall (2009) never seem to find it. Thus, in "The Beauty" or "Children as Enemies" we see many Chinese immigrants coming to the USA in search of the American dream. They manage to find it somehow, but they are never fully satisfied. Why so? Are cultural barriers so difficult to overcome?

Ha Jin: That's part of it. The American dream is misrepresented in my fiction. It is presented as too fabulous a vision and the result is that there is a huge gap between reality and the possibility of a dream. In other words, people have too high hopes for immigration and they often tend to neglect the difficulties accompanying it. It is a huge disruption in a person's life - you have to uproot and plant yourself in another soil, whether you can survive or not is the question . But people never think of it in that way. They think that America is a land where everybody can thrive and, even though some people can, this is not always the case . 
inteRvieWeR: The place names appearing in your stories seem to be a quite distinctive trademark in your fiction. What lies behind such places as "Golden County", "Dismount Fort", "Muji City" or "Dalian City"?

Ha Jin: Some of those names are fictional, for example, Muji City. I used the same place name in my novel Waiting. While I was working on this novel, I needed a city with an army hospital but the real city does not have a hospital. Thus, I had to move an army hospital to that city, the result being I had to give a fictional name to that city. Other places such as Dismount Fort, Golden County or Dalian City, the examples you mentioned, are actual names and they do exist. They are however literal translations from the Chinese and, in the case of Dismount Fort, its name alludes to the idea of "dismounting from a horse". It was a post for troops so that place was a resting place before soldiers continued their expeditions .

inteRvieWeR: In your stories set in China, men and women live differently according to a strict code of morality and behaviour, e.g. "In Broad Daylight", "Taking a Husband" (Under the Red Flag) or "The Bridegroom" (The Bridegroom), but once in America, both live similarly, there is no clear distinction between the male/female migration experience. Do you think men and women immigrants live the process of adaptation similarly? Are there any differences?

Ha Jin: There are differences but due to its length, the short story does not really allow to answer that . In my novel A Free Life, I talk about those differences . Women tend to adapt better, not physically but because they have different responsibilities - cooking, taking care of children - whereas husbands tend to go out. In a sense, I noticed that men tend to get frustrated more easily. So there are differences . In China, women do most of the housework and domestic chores . In the United States, there are lots of amenities, for instance, washing machine, air conditioning, gas stove, etc. Thus, while they are now available in China, they were rarities in China in the old days . Naturally, many women have found the immigrant experience rather liberating .

inteRvieWeR: Is there a real change in the traditional malelfemale roles once they live in the US? Do you think they live differently at home (traditional separation of the sexes) and in public?

Ha Jin: It is a fact that women have become often very powerful in the household . If a man cannot find a job, the power dynamics in the family might change.

inteRvieWeR: There are some stories dealing with academic and university life, and most of them show how pernicious the control of the government over higher education can be. Thus, in stories such as "Shame" (A Good Fall), the reader gets the impression that academic life in China is poor and limited and also strictly controlled by the government. Does this fictional view match reality in current China? 
Ha Jin: Yes, it is still like that. We should keep in mind that almost all the colleges and universities, I would say more than $90 \%$ of them, are run by the state. This means that the state can fire you at any time. There are laws that explicitly forbid doing anything against the country - but that is a very loose charge . In the past, many professors were exposed by their students who had become some kinds of agents working for the Chinese government. Thus, they wouldn't fire you out of hand, but they would send you to a remote place. Some scholars were banished to different places .

inteRvieWeR: Would this happen in much more Westernized cities, such as Canton or Shanghai?

Ha Jin: Oh, it did not make a difference because every university is owned by the state . Nonetheless, in terms of a cultural environment, in the South or coastal cities that might be looser. But when we talk about the political control, the Party's hand is still everywhere

inteRvieWeR: In such stories as "An Official Reply (The Bridegroom) or "Shame" (A Good Fall), university researchers seem to have little or no opportunities to develop their work in China. Is migration the only chance to succeed? Are there new possibilities and/ or changes for academics?

Ha Jin: Well, migration is not a chance for most people. The most discouraging part is that after existing in the oppressive environment for a while, a lot of people lose hope and become very cynical. They cannot see a reason for making an effort, so they don't make an effort anymore. As a result, they become very dangerous . Imagine what these people might teach students, so what kind of message or mentality they are going to communicate to their students. So it can get very depressing .

inteRvieWeR: But we tend to see that things might have changed in China because though still a comunist country, you find a large number of millionaires and the country is opening up to the Western World more and more...

Ha Jin: Yes, on the street... in terms of economy, people's everyday life, even sex, everything is much more relaxed than it used to be in the past. However, if we talk about culture, publications, social politics, academia, all these fields are still under a tight government control that I feel is even tighter than ten years ago .

inteRvieWeR: Can you predict what your next short story collection will be about?

Ha Jin: I cannot . Probably I will write something artistically more challenging . At the moment I have no plans at all .

\section{REFERENCES}


Fay, SaRah. 2009. “Ha Jin. The Art of Fiction No 202.” The Paris Review, 191 (Winter) . Retrieved 25 Mayo 2013 . <http://www .theparisreview .org/interviews/5991/ the-art-of-fiction-no-202-ha-jin>.

GaRdneR, Dwight. 2000. "Ha Jin's Cultural Revolution.” The New York Times, 6 February: 38-41. Retrieved 25 July 2014. <http:// www.nytimes.com/2000/02/06/ magazine/ha-jin-s-cultural-revolution.html>.

Gong, HaoMin. 2014. "Language, Migrancy, and the Literal: Ha Jin's Translation Literature ." Concentric: Literary and Cultural Studies, 40 .1: 147-167 .

Jin, Ha . 1990 . Between Silences . Chicago: The University of Chicago Press .

_ 1996a . Facing Shadows. New York: Hanging Loose Press.

_ 1996b . Ocean of Words. New York: Vintage.

ـ 1997 . Under the Red Flag. South Royalton, VT: Zoland Books.

_ 2000a . The Bridegroom. New York: Vintage.

— 2000b. Waiting. New York: Vintage.

—. 2004 . War Trash. New York: Vintage.

- 2008 . The Writer as Migrant . Chicago: The University of Chicago Press .

— 2009. A Good Fall. New York: Pantheon.

— 2011 . Nanjing Requiem. New York: Pantheon Books.

- 2014 . A Map of Betrayal. New York: Pantheon.

junckeR, ClaRa. 2010. “The New Americans: Ha Jin's Immigration Stories.” Ed. Tanfer Emin Tunc \& Elisabetta Marino. Positioning the New: Chinese American Literature and the Changing Image of the America Literary Canon . Newcastleupon-Tyne: Cambridge Scholars . 216-28 .

Kong, Belinda. 2012 . "Diasporic Exceptionality: Maxine Hong Kingston's 'The Brother in Vietnam' and Ha Jin's 'A Good Fall."' Ed. Deborah Wattley Poe. Between Worlds: An Anthology of Contemporary Fiction and Criticism, New York, NY: Peter Lang. 203-14.

MaRtin, Holly E. 2011. "Falling Into America: The Downside of Transnational Identities in Ha Jin's A Good Fall ." Transnational Literature, 4 .1: n .p .

O'ConnoR, FRank. 2014 (1962) . The Lonely Voice . A Study of the Short Story . Hoboken, NJ: Melville House Publishing.

ThoMas, John D . 1999 . “Across an Ocean of Words .” Emory Magazine (Spring): n.p. Retrieved 9 October 2013. <http://www.emory.edu/EMORY_MAGAZINE/ spring98/ hajin.html>

WeinbeRgeR, Eliot. 2006 . "Enormous Changes ." PEN America: A Journal for Writers and Readers, 7: 38-49 . 
Zhang, Hang. 2002. "Bilingual Creativity in Chinese English: Ha Jin's In the Pond." World Englishes: Journal of English as an International and Intranational Language, 21 .2: 305-315 . 
